\title{
Microalgal biofactories: a promising approach towards sustainable omega-3 fatty acid production
}

\author{
T. Catalina Adarme-Vega ${ }^{1}$, David K Y Lim ${ }^{1}$, Matthew Timmins ${ }^{2}$, Felicitas Vernen ${ }^{1}$, Yan Li ${ }^{1,2}$ and Peer M Schenk ${ }^{1 *}$
}

\begin{abstract}
Omega-3 fatty acids eicosapentaenoic acid (EPA) and docosahexaenoic acid (DHA) provide significant health benefits and this has led to an increased consumption as dietary supplements. Omega-3 fatty acids EPA and DHA are found in animals, transgenic plants, fungi and many microorganisms but are typically extracted from fatty fish, putting additional pressures on global fish stocks. As primary producers, many marine microalgae are rich in EPA (C20:5) and DHA (C22:6) and present a promising source of omega-3 fatty acids. Several heterotrophic microalgae have been used as biofactories for omega-3 fatty acids commercially, but a strong interest in autotrophic microalgae has emerged in recent years as microalgae are being developed as biofuel crops. This paper provides an overview of microalgal biotechnology and production platforms for the development of omega-3 fatty acids EPA and DHA. It refers to implications in current biotechnological uses of microalgae as aquaculture feed and future biofuel crops and explores potential applications of metabolic engineering and selective breeding to accumulate large amounts of omega-3 fatty acids in autotrophic microalgae.
\end{abstract}

Keywords: Docosahexaenoic acid, DHA, Eicosapentaenoic acid, EPA, Microalgae, Omega-3 fatty acids, Polyunsaturated fatty acids

\section{Introduction}

Omega-3 $(\omega-3)$ fatty acids are polyunsaturated fatty acids (PUFAs) and essential components for the growth of higher eukaryotes [1]. Nutritionally, eicosapentaenoic acid (EPA, 20:5) and docosahexaenoic acid (DHA, 22:6) are the most important fatty acids belonging to this group of bioactive compounds. These long chain omega3 fatty acids provide significant health benefits to the human population, particularly in reducing cardiac diseases such as arrhythmia, stroke and high blood pressure [2,3]. Additionally, they have been seen to offer beneficial effects to depression, rheumatoid arthritis and asthma [4-6].

Currently, the principal source of EPA and DHA for human consumption is marine fatty fish such as salmon, mullet and mackerel $[7,8]$. However, global catches have been in decline since the late 1980s and the number of

\footnotetext{
* Correspondence: p.schenk@uq.edu.au

${ }^{1}$ Algae Biotechnology Laboratory, School of Agriculture and Food Sciences,

The University of Queensland, Brisbane, QLD 4072, Australia Full list of author information is available at the end of the article
}

overfished stocks has been increasing exponentially since the 1950s [9,10]. Furthermore, the presence of chemical contaminants (e.g. mercury) in fish oil can be harmful to consumers [11,12]. In addition, fish oil is not suitable for vegetarians and the odour makes it unattractive. There is a variety of alternative EPA and DHA sources such as bacteria, fungi, plants and microalgae that are currently being explored for commercial production. Fungi require an organic carbon source and typically long growth periods [13], plants need arable land, have longer growth times and have no enzymatic activity for producing long chain PUFAs EPA and DHA, unless genetically modified [14]. Microalgae are the initial EPA and DHA producers in the marine food chain and can naturally grow fast under a variety of autotrophic, mixotrophic and heterotrophic culture conditions with high long chain $\omega-3$ fatty acid production potential [15]. Autotrophic and mixotrophic microalgae fix atmospheric carbon dioxide during photosynthesis, can potentially grow on non-arable land and have short harvesting times [16,17]. A comparison shows that microalgae can reach much higher EPA

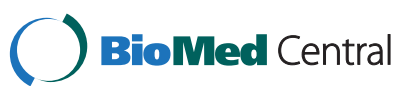

(c) 2012 Adarme-Vega et al.; licensee BioMed Central Ltd. This is an Open Access article distributed under the terms of the Creative Commons Attribution License (http://creativecommons.org/licenses/by/2.0), which permits unrestricted use, distribution, and reproduction in any medium, provided the original work is properly cited. 
and DHA contents and productivities compared with other possible sources (Table 1). In particular heterotrophic microalgae are well established as an alternative source of DHA and are added to infant milk formula or other food [18]. Other microalgal products are used as food additives, animal feed (including aquaculture), vitamins, pigments, pharmaceutical compounds, cosmetics and potentially as a biofuel source $[17,19,20]$. The development of an efficient large-scale cultivation system for the commercial production of EPA and DHA would address a major global need. Here, we review the potential of autotrophic eukaryotic microalgae as biofactories for large-scale production of omega-3 fatty acids.

\section{Microalgae in aquatic food chains: the initial omega-3 producers}

Microalgae are by far the most abundant primary producers that can be found in most aquatic systems, photosynthetically converting light energy and carbon dioxide $\left(\mathrm{CO}_{2}\right)$ into biomass such as carbohydrates [44], proteins [45] and lipids [46]. Under high nutrient supply (eutrophic conditions), algae blooms commonly occur as microalgal cell density drastically increases [47]. During microalgal blooms the limitation of nutrients or light halters the increase of biomass. If nutrients, but not light, are limiting, this leads to the accumulation of photosynthetic bioproducts such as lipids and carbohydrates. These serve as storage products in order to survive the stressful growth limiting conditions, after which a large number of cells die $[47,48]$. Algal biomass is subsequently degraded by microorganisms, consuming large amounts of oxygen. As a result an anaerobic zone in the water is formed (Figure 1). In extreme cases, this can lead to anaerobiosis of the entire water body, causing the death of plants and animals in the waterway; interestingly this process is also believed to have been the key factor for large-scale oceanic anoxic events that led to fossil mineral oil deposition [17].

Importantly, microalgae are also the primary producers of EPA and DHA that are eventually accumulated through the various trophic levels. Changes in microalgal lipid content are carried on up the food chain (Figure 2), impacting the growth and dietary make-up of zooplankton, crustacean larvae, mollusc and some fish [49]. This subsequently affects the accumulation of EPA and DHA fatty acids in higher organisms and humans. Consequently, lipid profiles in microalgae play a vital role in maintaining the integrity of the world's aquatic food webs.

\section{The nutritional importance of microalgae and EPA content in aquaculture}

Microalgae are essential to the aquaculture industry which has grown substantially over the last 10 years
Table 1 Comparison of EPA and DHA fatty acid contents as percentage from total lipids in examples of bacteria, fungi, fish, transgenic plants and microalgae

\begin{tabular}{|c|c|c|}
\hline Organism & $\begin{array}{l}\% \text { EPA and/or DHA } \\
\text { production }\end{array}$ & Reference \\
\hline \multicolumn{3}{|l|}{ Bacteria } \\
\hline Shewanella putrefaciens & 40.0 EPA & [21] \\
\hline Alteromonas putrefaciens & 24.0 EPA & {$[22]$} \\
\hline Pneumatophorus japonicus & 36.3 EPA & [23] \\
\hline Photobacterium & 4.6 EPA & [24] \\
\hline \multicolumn{3}{|l|}{ Fungi } \\
\hline Thraustochytrium aureum & $62.9 \mathrm{EPA}+\mathrm{DHA}$ & [1] \\
\hline Mortierella & $20.0 \mathrm{EPA}$ & {$[25]$} \\
\hline Mortierella & 13.0 EPA & {$[26]$} \\
\hline Pythium & 12.0 EPA & {$[27]$} \\
\hline Pythium irregulare & 8.2 EPA & {$[28]$} \\
\hline \multicolumn{3}{|l|}{ Fish } \\
\hline Merluccius productus & 34.99 EPA + DHA & [29] \\
\hline Theragra chalcogramma & 41.35 EPA + DHA & [29] \\
\hline Hypomesus pretiosus & 33.61 EPA + DHA & [29] \\
\hline Sebastes pinniger & $29.8 \mathrm{EPA}+\mathrm{DHA}$ & {$[29]$} \\
\hline Oncorhynchus gorbusha & $27.5 \mathrm{EPA}+\mathrm{DHA}$ & [29] \\
\hline Mallotus villosus & $17.8 \mathrm{EPA}+\mathrm{DHA}$ & [29] \\
\hline Sardinops sagax & 44.08 EPA + DHA & {$[29]$} \\
\hline Clupea harengus pallasi & 17.32 EPA + DHA & {$[29]$} \\
\hline \multicolumn{3}{|l|}{ Plant (transgenic) } \\
\hline Soybean & 20.0 EPA & {$[30]$} \\
\hline Brassica carinata & 25.0 EPA & {$[31]$} \\
\hline Nicotiana benthamiana & 26.0 EPA & {$[32]$} \\
\hline \multicolumn{3}{|l|}{ Microalgae } \\
\hline Nannochloropsis sp. & 26.7 EPA + DHA & {$[33]$} \\
\hline Nannochloropsis oceanica & 23.4 EPA & {$[34]$} \\
\hline Nannochloropsis salina & $\sim 28 \mathrm{EPA}$ & {$[35]$} \\
\hline Pinguiococcus pyrenoidosus & 22.03 EPA + DHA & {$[36]$} \\
\hline Thraustochytrium sp. & 45.1 EPA + DHA & {$[37]$} \\
\hline Chlorella minutissima & 39.9 EPA & {$[38]$} \\
\hline Dunaliella salina & 21.4 EPA & {$[39]$} \\
\hline Pavlova viridis & 36.0 EPA + DHA & {$[40]$} \\
\hline Pavlova lutheri & 27.7 EPA + DHA & [41] \\
\hline Pavlova lutheri & 41.5 EPA + DHA & {$[42]$} \\
\hline Isocrysis galbana & $\sim 28.0 \mathrm{EPA}+\mathrm{DHA}$ & {$[43]$} \\
\hline
\end{tabular}

[50,51]. The successful cultivation of oysters, scallops and mussels is dependent on the $\omega-3$ fatty acids from microalgal feedstock. The polyunsaturated omega-3 fatty acids EPA and DHA derived from microalgae (e.g. Isochrysis, Tetraselmis, Chaetoceros, Thalassiosira, Nannochloropsis) are also known to be essential for 


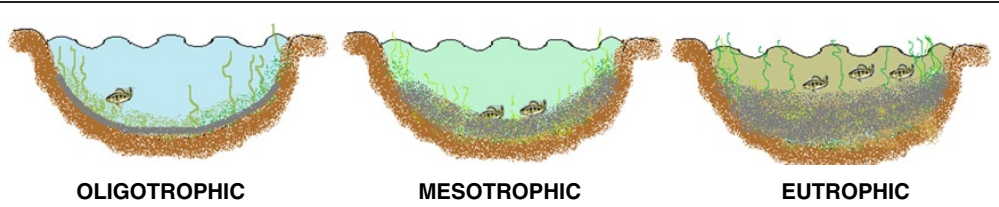

Figure 1 Algal blooms in eutrophic aquatic systems use up nutrients and compete for light. If nutrients become limiting first, microalgae may accumulate large amounts of lipids and/or carbohydrates as a survival strategy. The decay of organic matter by bacteria uses up oxygen causing localized anaerobiosis zones. These zones (here shown as grey areas) are present in all aquatic systems but occur at much deeper levels under mesotrophic or oligotrophic conditions. Photosynthetic microalgae require polar polyunsaturated lipids in particular for membrane where fluidity is critical, while most storage lipid occurs in the form of lipid bodies containing triacylglycerides. These typically vary in their composition and typically contain a mixture of saturated and unsaturated fatty acids for storage.

healthy development of various bivalve larvae $[52,53]$. Prior research on the scallop Pecten maximus has shown a direct relationship between the fatty acid profile of female gonads and the fatty acid composition of the eggs [54]. The increase of EPA and DHA from an algal diet significantly increased the concentration of fatty acids in the digestive gland (78\%) of scallops as well as the female (57\%) and male gonads (51\%). It appears that dietary lipids are stored in the digestive gland and are later transferred to the developing female gonad. These dietary lipids are then incorporated into the eggs and can significantly improve their quality.
This in turn improves the hatching rate of eggs and hatching rates have been linked to high contents of EPA and DHA [53]. Aside from bivalve culture, microalgae are also used as food additives to improve the flesh color of salmon [55], as well as inducing a range of other biological activities such as survival and resistance [19].

The selection of suitable microalgae species for aquaculture is very important. Firstly, a candidate species must be adaptable to mass culture with high growth rates and lipid content $[34,56]$. Furthermore, it must tolerate moderate fluctuations of temperature, light and

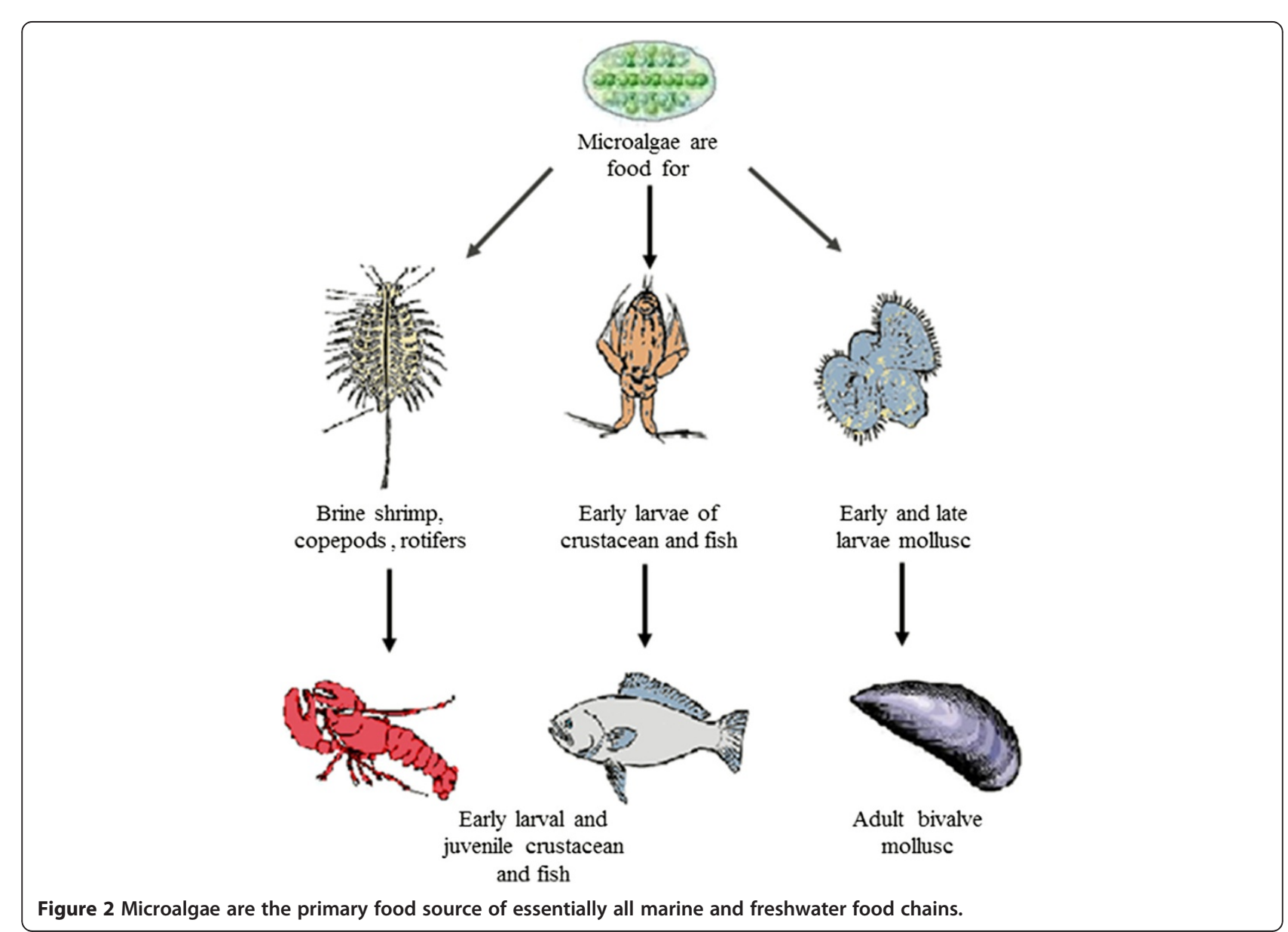


nutrients[57,58]. A microalgae species used for aquaculture must also have the appropriate size for ingestion (e.g. from 1 to $15 \mu \mathrm{m}$ for filter feeders; 10 to $100 \mu \mathrm{m}$ for grazers) and be readily digestible [56]. Finally, they must possess a suitably high lipid composition with long chain polyunsaturated fatty acids and be free of toxins for target culture species $[34,56]$. Selection of the suitable microalgal diet is of paramount importance to aquaculture hatchery and nursery success [58]. At present, the most widely cultured species for aquaculture hatcheries and nurseries include Chaetoceros calcitrans, Isochrysis galbana, Pavlova lutheri, Pseudoisochrysis paradoxa, Tetraselmis suecica and Skeletonema costatum. Other genera include Spirulina, Dunaliella, Chlorella, Thalassiosira, Isochrysis and Nannochloropsis [49].

\section{Health benefits of microalgal omega- 3 fatty acids}

Omega-3 fatty acids represent an important structural component of human cell membranes, particularly neuronal cells [59]. The consumption of EPA and DHA supplements has been shown to prevent cardiovascular, nervous system and inflammatory conditions [60]. With regards to cardiovascular health, regular consumption of $\omega-3$ fatty acids can help reduce the risk of hypertension, thrombosis, myocardial infarction and cardiac arrhythmias [61]. This occurs because $\omega-3$ fatty acids increase the high-density lipoprotein/low-density lipoprotein (HDL/LDL) ratio and decrease the total cholesterol/ HDL ratio [61]. In addition to cardiovascular benefits, omega-3 fatty acids have also demonstrated positive effects on brain function and the nervous system[62]. In pregnant women, the adequate intake of EPA and DHA is crucial for healthy development of the fetal brain [63]. In infants, arachidonic acid (ARA), an omega- 6 fatty acid, and DHA are also required for normal growth and functional development [64]. Interestingly, increased consumption of DHA may also diminish the severity of depression [65]. Immuno-modulatory effects have been observed when $\omega-3$ fatty acids were used in the treatment of inflammatory conditions such as rheumatoid arthritis, Crohn's disease, ulcerative colitis, psoriasis, asthma, lupus and cystic fibrosis [66,67]. Children ingesting fish oil more than once a week had a lower probability of suffering from asthma [68]. Increasing the levels of DHA and EPA in patients with rheumatoid arthritis and ulcerative colitis has also been found to reduce pain and improve conditions, although the modes of operation are unclear at this point $[69,70]$.

There is currently a large demand for microalgae in the nutraceutical and pharmaceutical industry due to their health-promoting effects. Microalgal-derived PUFA, such as ARA and DHA are added as fortifications to infant formulae-an industry that is worth $\$ 10$ billion per annum alone. To date, microalgal extracts can be found in many face and skin care products, e.g. anti-aging cream, refreshing or regenerative care products, sun cream, emollient and anti-irritant in peelers [19]. Dermochlorella is actually extracted from Chlorella vulgaris, which can stimulate collagen synthesis in skin supporting tissue regeneration and wrinkle reduction [71]. Protulines is a protein-rich extract from Arthrospira (Spirulina), which helps combat early skin aging, exerting a tightening effect and preventing wrinkle formation [72].

\section{Omega-3 fatty acid production in microalgae}

Microalgae produce a variety of compounds to help in the adaptation and survival of different environmental conditions. Many marine microalgal strains have oil contents of between $10-50 \%,(\mathrm{w} / \mathrm{w})$ and produce a high percentage of total lipids (up to $30-70 \%$ of dry weight) [1]. The accumulation of fatty acids is closely linked to microalgal growth stages, functioning as an energy stockpile during unfavourable conditions or cell division. Omega-3 is accumulated due to its high energy content, as well as the good flow properties crucial for cellular functions $[73,74]$. To date, the $\omega-3$ fatty acid content of numerous microalgae strains have been studied. Strains from the genera Phaeodactylum, Nannochloropsis, Thraustochytrium and Schizochytrium have demonstrated high accumulation of EPA and/or DHA. Phaeodactylum tricornutum [38] and Nannochloropsis sp. [75] demonstrated an EPA content of up to 39\% of total fatty acids, while strains such as Thraustochytrium [76] and Schizochytrium limacinum [77] contained a DHA percentage of between $30-40 \%$ of total fatty acids when grown heterotrophically. High biomass and commercially acceptable EPA and DHA productivities are achieved with microalgae grown in media with optimized carbon and nitrogen concentrations and controlled $\mathrm{pH}$ and temperature conditions [78]. High oil production, including DHA from Schizochytrium $(50 \% \mathrm{w} / \mathrm{w})$, can be obtained as a result of high growth rate by controlling of nutrients such as glucose, nitrogen, sodium and some other environmental factors, such as oxygen concentrations as well as temperature and $\mathrm{pH}$, achieving high cell densities and DHA productivities [1].

\section{Induction of omega-3 production in autotrophic microalgae}

An increase in microalgal lipid content can be induced by a sudden change of growth conditions. The accumulation of starch and/or lipids reserves is considered a survival mechanism in response to growth-limiting stresses [17], such as UV radiation [79], temperature [80] and shock or nutrient deprivation $[81,82]$, as long as light conditions are present that still allow efficient photosynthesis. For example, during nutritional deprivation (e.g. nitrogen) and 
under the provision of light, cellular division of many marine or brackish microalgae is put on hold and cells begin to accumulate lipids [83], leading to a 2-3 fold increase in lipid content. Both total lipid and omega-3 fatty acid production can be adjusted by varying growth conditions. The diatom Phaeodactylum tricornutum can be induced to increase its lipid level from $81.2 \mathrm{mg} / \mathrm{g}$ of culture dry weight to $168.5 \mathrm{mg} / \mathrm{g}$ dry weight [38]. Similarly, Nannochloropsis sp. [84] and Dunaliella sp. [85] can achieve a total lipid content of up to $47 \%$ and $60 \%$ of dry ash weight by modifying the light intensity, temperature and salinity levels. Lipid abundance has also been shown to increase due to anaerobic sulphur deprivation [86] or the addition of extra nutrients [87].

Omega-3 fatty acid biosynthesis can be stimulated by a number of environmental stresses, such as low temperature, change of salinity or UV radiation. For example, Pavlova lutheri increased its relative EPA content from 20.3 to $30.3 \mathrm{M} \%$ when the culture temperature was reduced to $15^{\circ} \mathrm{C}$ [88]. Similarly, Phaeodactylum tricornutum had a higher EPA content when the temperature was shifted from $25^{\circ} \mathrm{C}$ to $10^{\circ} \mathrm{C}$ for $12 \mathrm{~h}$ [89]. An increase in PUFAs is expected as these fatty acids have good flow properties and would be predominately used in the cell membrane to maintain fluidity during low temperatures. Salinity may also regulate PUFA biosynthesis, although not in a consistent manner. For example, Crythecodinium cohnii ATCC 30556 increased its total DHA content up to $56.9 \%$ of total fatty acids when cultured in $9 \mathrm{~g} / \mathrm{L} \mathrm{NaCl}$. Other treatments that cause the generation of reactive oxygen species and lipid peroxidation also result in higher PUFA contents. For example, Phaeodactylum tricornutum increased its EPA content up to $19.84 \%$ when stressed with UV light [90]. Some of the increased PUFAs are used to repair membrane damage but as PUFAs contain many double bonds, these also act as an antioxidant by scavenging free radicals.

\section{Metabolic engineering of microalgae for higher omega-3 contents}

Apart for external stresses, metabolic engineering is another promising approach to increase the production of fatty acids in microalgae (for a recent review see Schuhmann et al. [91]). Genes encoding key enzymes involved in the fatty acid biosynthesis have been identified in Ostreococcus tauri [92], Thalassiosira pseudonana [93-95], Phaeodactylum tricornutum [96,97] and in particular the model organism Chlamydomonas reinhardtii [98]. At present, the mechanisms involved in the fatty acid biosynthetic pathways in microalgae have not been extensively studied and most information has been gathered from studies on plant metabolism. Briefly, de novo fatty acid synthesis occurs in the chloroplast and involves the carboxylation and condensation of acetyl-CoA to malonyl-CoA, with further elongation reactions occurring with malonyl ACP as substrate to create long chain fatty acids. Long chain fatty acids are transferred to glycerol-3-phosphate to form triacylglycerol (TAG) via the metabolic intermediate phosphatidic acid in the endoplasmic reticulum [99]. Synthesis of $\omega-3$ fatty acids occurs via the elongation and desaturation of long chain fatty acids (Figure 3).

Work has been performed to create recombinant sources of $\omega-3$ fatty acids in a variety of systems with some success [101,102]. Canola (Brassica napus) seeds have been produced which overexpress the $B$. napus $\Delta 15$ desaturase, as well as the $\Delta 6$ and $\Delta 12$ desaturases from the commercially grown fungus Mortierella alpina to synthesize the $\omega-3$ fatty acid stearidonic acid (SDA) [14]. It may be possible in the future to produce $\omega-3$ fatty acids in microalgae in much larger quantities by regulating the expression of similar enzymes. A promising cisgenic approach for microalgae maybe to increase EPA or DHA production by overexpressing at least some of their native elongases and desaturases. It may be necessary to use promoters inducible by external stimuli rather than constitutive promoters that may interfere with normal cell function and growth. Another, yet unexplored option may lie in the inhibition of PUFA degradation. $\beta$-oxidation of fatty acids occurs in the peroxisomes but before PUFAs can be metabolized, saturases are required to fill in the double bonds. Mutations in one or several saturases may result in less efficient $\beta$-oxidation of PUFA and a higher percentage of these fatty acids. However, at present the mechanism behind the selection and storage of fatty acids for triacylglycerol production remains unclear.

\section{Extraction and purification of omega-3 fatty acids from microalgal biomass}

Figure 4 summarizes an integrated system for the largescale production of microalgal bio-products. A microalgae strain is cultivated to increase cell density using photobioreactors, open ponds, race ways or hybrid systems. Algal cells are separated from culture media by filtration, flocculation or centrifugation, followed by drying to improve extraction [1]. Lipid extraction is then commonly performed using a non-water miscible organic solvent. A typical extraction protocol in small scale is often based on the method of Bligh and Dyer [103], which uses a solvent mixtures made of methanol/ chloroform for the cell disruption and lipid extraction. Larger scale extraction is typically carried out with hexane as a solvent. Subsequently, unsaturated fatty acids are separated from the total lipids by fractional (molecular) distillation or winterization, whereby oil temperature is reduced to precipitate the more saturated lipids. Further processing to improve the quality, shelf-life and quantity of 


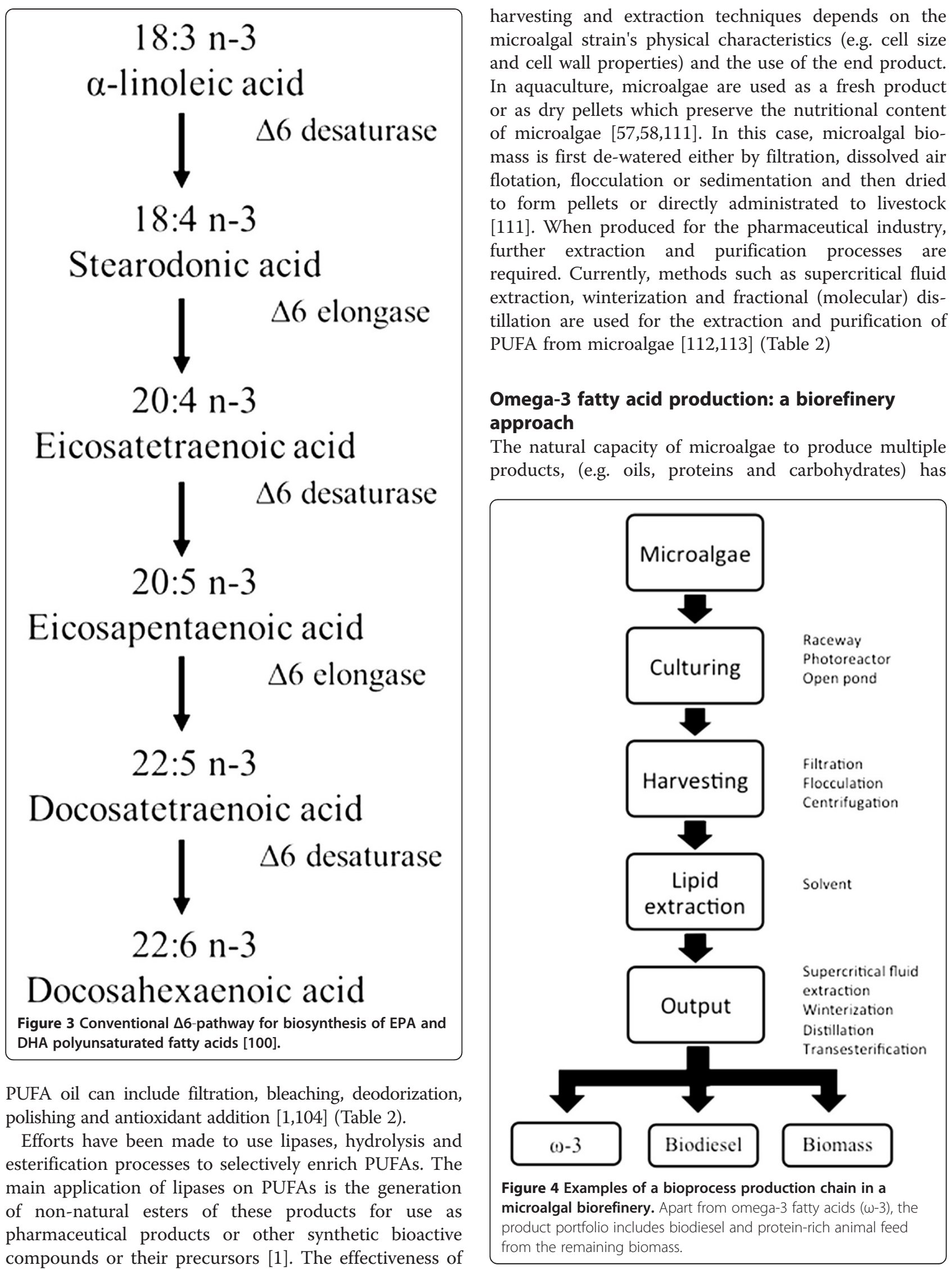


Table 2 Summary of PUFA enrichment processes

\begin{tabular}{|c|c|}
\hline Method & Procedure \\
\hline Molecular distillation (Fractional distillation) & $\begin{array}{l}\text { Purification of fatty acid esters in a vacuum system based on the different boiling points of different } \\
\text { fatty acids [105]. }\end{array}$ \\
\hline Molecular sieves & Separation via membrane permeability and selectivity [106]. \\
\hline PUFA transformations & $\begin{array}{l}\text { Esterification of PUFA and free fatty acids to produce esters (ethyl-, glyceryl-, sugar-, other). } \\
\text { Inter-esterification to enrich lowly unsaturated fatty acids with PUFA [107]. }\end{array}$ \\
\hline Super Critical Fluid Extraction & Optimization of lipid solubility and fractionation in supercritical $\mathrm{CO}_{2}$ [108]. \\
\hline Urea complexation & $\begin{array}{l}\text { Solubilization of fatty acids, adding urea and ethanol to saturation point exposing it to heat. } \\
\text { Recovery of product by filtration [109]. }\end{array}$ \\
\hline Winterization & Temperature reduction to render more saturated fats insoluble [110]. \\
\hline
\end{tabular}

encouraged the development of a biorefinery concept for processing. Akin to the petrochemical industry, where crude oil is processed to yield petroleum and a range of other chemicals, microalgae can be processed to produce a range of bioproducts. Different industries are able to use different algal products. For instance, the pharmaceutical and nutraceutical industries use high value bioactive products such as $\omega-3$ fatty acids and carotenoids; the transport industry can use fatty acids from TAG for biodiesel, the chemical industry can use products such as glycerine, while the majority of the biomass can be used by agriculture and aquaculture as animal feed $[114,115]$. Additional processes that address nutrient recycling and carbon sequestration can be used by anaerobic digestion of wet biomass and pyrolysis for the production of biochar.

Undoubtedly, the biggest interest in microalgal use is for biodiesel production. It potentially represents a more sustainable alternative to fossil fuels as microalgal production facilities do not need to compete for arable land or freshwater. Furthermore, in comparison to land plants, 10-400 times more energy per acre can potentially be produced from microalgae. Although there has been considerable interest and research over the past years into microalgal biofuel production [83], no commercial enterprise has successfully established itself as a supplier of autotrophically derived algal biofuels for any duration. Nevertheless, decreasing fossil fuel reserves and increasing fuel costs continue to drive research targeted towards economically viable production of microalgal biodiesel, with the level of improvement necessary now appearing attainable $[15,17]$. There is confidence among companies producing microalgae that the production of a high value product, such as omega-3 from microalgae, will further assist in the establishment of the microalgae industry. Several companies have (at least temporarily) shifted their focus from algal biodiesel production, to high value products such as omega-3 and protein-rich biomass as animal feed (e.g. Aurora Algae, MBD, Cellana).

\section{Conclusions}

Global fish stocks are declining and cannot provide a sustainable source of omega-3 fatty acids. Heterotrophic microalgae have been used for the production of omega-3 fatty acids, in particular DHA. However, as the primary producers of PUFAs, the use of autotrophic microalgae for large-scale production of omega-3 fatty acids has recently attracted a lot of interest. Autotrophic microalgae do not require an organic carbon source and hence may avoid the problems faced for heterotrophic cultures that can easily get contaminated with other microorganisms. In a biorefinery concept, omega-3 fatty acids can be separated from microalgal lipids which would be widely used for biodiesel production, while biomass can find uses as valuable protein-rich animal feed which could free up arable land for food production. If carried out at a large scale this would address three major areas of importance: human health, transportable energy and food security.

Over the past decade, algae biotechnology has grown steadily into a global industry with increasing numbers of entrepreneurs attempting to utilize its biochemical diversity for a wide array of applications. At present, achieving economically viable production of microalgal lipids is still a major challenge, but strong potential stems from the fact that these microbial cell factories have not been domesticated and are not as well studied compared to agricultural crops [102]. Indeed, of approximately 40,000 algal species, only a few thousand strains are kept in collections, a few hundred are investigated for chemical content and approximately half a dozen are cultivated in industrial quantities. Therefore, continued isolation and screening of microalgae is required, as well as more in depth studies into algal physiology, biochemistry and genetics. Meanwhile the processes for algae cultivation, harvesting and oil extraction need to be further improved in efficiency and costs. As omega-3 fatty acids are one of the most valuable products from microalgae, they are likely to be the "game-changer" towards large-scale economical microalgae cultivation that will catalyze the production of other important algal bioproducts. 


\section{Competing Interest}

The authors declare that they have no competing interests.

\section{Acknowledgements}

This work was supported by the Australian Research Council and Queensland Sea Scallops Pty Ltd. The funding bodies had no influence in the writing of the manuscript and in the decision to submit the manuscript for publication.

\section{Author details}

${ }^{1}$ Algae Biotechnology Laboratory, School of Agriculture and Food Sciences, The University of Queensland, Brisbane, QLD 4072, Australia. ${ }^{2}$ Centre for Metabolomics, School of Chemistry and Biochemistry, The University of Western Australia M313, 35 Stirling Highway, Crawley, WA 6009, Australia.

\section{Authors' contributions}

All authors contributed in data collection from literature and writing of the manuscript including figures and tables. All authors have read and approved the final manuscript.

Received: 25 April 2012 Accepted: 06 July 2012

Published: 25 July 2012

\section{References}

1. Ward OP, Singh A: Omega-3/6 fatty acids: alternative sources of production. Process Biochem 2005, 40(12):3627-3652.

2. Romieu I, Tellez-Rojo MM, Lazo M, Manzano-Patino A, Cortez-Lugo M, Julien $P$, Belanger MC, Hernandez-Avila M, Holguin F: Omega-3 fatty acid prevents heart rate variability reductions associated with particulate matter. Am J Respir Crit Care Med 2005, 172(12):1534-1540.

3. Von Schacky C: Omega-3 fatty acids: antiarrhythmic, proarrhythmic or both? Curr Opin Clin Nutr Metab Care 2008, 11(2):94-99.

4. Von Schacky C, Harris WS: Cardiovascular benefits of omega-3 fatty acids. Cardiovasc Res 2007, 73(2):310-315.

5. Balk E, Chung M, Lichtenstein A, Chew P, Kupelnick B, Lawrence A, DeVine D, Lau J: Effects of omega-3 fatty acids on cardiovascular risk factors and intermediate markers of cardiovascular disease. Evid Rep Technol Assess (Summ) 2004, (93):1-6.

6. Adams PB, Lawson S, Sanigorski A, Sinclair AJ: Arachidonic acid to eicosapentaenoic acid ratio in blood correlates positively with clinical symptoms of depression. Lipids 1996, 31(1):157-161.

7. Gunstone FD: Fatty acid and lipid chemistry: London:Black Academic and Professional: 1996.

8. Whitehead S: FAO species catalogue. In Clupeoid fishes of the world, Volume 7. Edited by NATIONS UNDPFAAOOTU. Rome: UNITED NATIONS: 1985.

9. AGDAFF: Australian government department of agriculture, fisheries and forestry. Fishery status reports 2007. 2007.

10. Worm B, Barbier EB, Beaumont N, Duffy JE, Folke C, Halpern BS, Jackson JBC, Lotze HK, Micheli F, Palumbi SR, et al: Impacts of biodiversity loss on ocean ecosystem services. Science 2006, 314(5800):787-790.

11. Mahaffey KR, Clickner RP, Jeffries RA: Methylmercury and omega-3 fatty acids: co-occurrence of dietary sources with emphasis on fish and shellfish. Environ Res 2008, 107(1):20-29.

12. Bourdon J, Bazinet T, Arnason T, Kimpe L, Blais J, White P: Polychlorinated biphenyls (PCBs) contamination and aryl hydrocarbon receptor (AhR) agonist activity of omega-3 polyunsaturated fatty acid supplements: implications for daily intake of dioxins and PCBs. Food Chem Toxicol 2010, 48(11):3093-3097.

13. Barclay WR, Meager KM, Abril JR: Heterotrophic production of long-chain omega-3-fatty-acids utilizing algae and algae-like microorganisms. J App/ Phycol 1994, 6(2):123-129.

14. Ursin VM: Modification of plant lipids for human health: development of functional land-based omega-3 fatty acids. J Nutr 2003, 133(12):4271-4274

15. Li Y, Qin JG, Moore RB, Ball AS: Perspectives of marine phytoplankton as a source of nutrition and bioenergy. In Marine phytoplankton. Edited by. New York: Nova Science Pub Inc; 2009, 14

16. Rubio-Rodríguez N, Beltrán S, Jaime I, de Diego SM, Sanz MT, Carballido JR: Production of omega-3 polyunsaturated fatty acid concentrates: a review. Innovat Food Sci Emerg Tech 2010, 11(1):1-12.
17. Schenk PM, Thomas-Hall SR, Stephens E, Marx UC, Mussgnug JH, Posten C, Kruse O, Hankamer B: Second generation biofuels: high-efficiency microalgae for biodiesel production. Bioenergy Res 2008, 1(1):20-43.

18. Van Tol EAF, Willemsen LEM, Koetsier MA, Beermann C, Stahl B: Improvement of intestinal barrier integrity. In EP patent 1,815,755. Edited by. 2009.

19. Spolaore $P$, Joannis-Cassan C, Duran E, Isambert A: Commercial applications of microalgae. J Biosci Bioeng 2006, 101(2):87-96.

20. Yamaguchi K: Recent advances in microalgal bioscience in Japan, with special reference to utilization of biomass and metabolites: a review. J Appl Phycol 1996, 8(6):487-502.

21. Yazawa K: Production of eicosapentaenoic acid from marine bacteria. Lipids 1996, 31(Suppl):S297-S300.

22. Yazawa K, Araki K, Okazaki N, Watanabe K, Ishikawa C, Inoue A, Numao N, Kondo K: Production of eicosapentaenoic acid by marine bacteria. J Biochem (Tokyo) 1988, 103(1):5-7.

23. Yazawa K, Araki K, Watanabe K, Ishikawa C, Inoue A, Kondo K, Watabe S, Hashimoto K: Eicosapentaenoic acid productivity of the bacteria isolated from fish intestines. Nippon Suisan Gakkaishi 1988, 54(10):1835-1838.

24. Ryan J, Farr H, Visnovsky S, Vyssotski M, Visnovsky G: A rapid method for the isolation of eicosapentaenoic acid-producing marine bacteria. J Microbiol Methods 2010, 82(1):49-53.

25. Jareonkitmongkol S, Shimizu S, Yamada $\mathrm{H}$ : Production of an eicosapentaenoic acid-containing oil by a $\Delta 12$ desaturase-defective mutant of Mortierella alpina 1S-4. J Am Oil Chem Soc 1993, 70(2):119-123

26. Jermsuntiea W, Aki T, Kawamoto S, Ono K: Metabolism and synthesis of lipids in the polyunsaturated fatty acid-producing fungus Mortierella alliacea. J Oleo Sci 2011, 60(1):11.

27. Athalye SK, Garcia RA, Wen Z: Use of biodiesel-derived crude glycerol for producing eicosapentaenoic acid (EPA) by the fungus Pythium irregulare. J Agric Food Chem 2009, 57(7):2739-2744

28. Liang $Y$, Zhao $X$, Strait $M$, Wen Z: Use of dry-milling derived thin stillage for producing eicosapentaenoic acid (EPA) by the fungus Pythium irregulare. Bioresour Technol 2012, 1:1.

29. Huynh MD, Kitts DD: Evaluating nutritional quality of pacific fish species from fatty acid signatures. Food Chem 2009, 114(3):912-918.

30. Kinney AJ, Cahoon EB, Damude HG, Hitz WD, Kolar CW, Liu Z: Production of very long chain polyunsaturated fatty acids in oilseed plants. Patent WO 2004, 71467:A2.

31. Cheng B, Wu G, Vrinten P, Falk K, Bauer J, Qiu X: Towards the production of high levels of eicosapentaenoic acid in transgenic plants: the effects of different host species, genes and promoters. Transgenic Res 2010, 19(2):221-229.

32. Petrie JR, Shrestha P, Mansour MP, Nichols PD, Liu Q, Singh SP: Metabolic engineering of omega-3 long-chain polyunsaturated fatty acids in plants using an acyl-CoA 6-desaturase with 3-preference from the marine microalga micromonas pusilla. Metab Eng 2010, 12(3):233240.

33. Hu H, Gao K: Optimization of growth and fatty acid composition of a unicellular marine picoplankton, Nannochloropsis sp., with enriched carbon sources. Biotechnol Lett 2003, 25(5):421-425.

34. Patil V, Källqvist T, Olsen E, Vogt G, Gislerød HR: Fatty acid composition of 12 microalgae for possible use in aquaculture feed. Aquac Int 2007, 15(1):1-9.

35. Van Wagenen J, Miller TW, Hobbs S, Hook P, Crowe B, Huesemann M: Effects of light and temperature on fatty acid production in Nannochloropsis salina. Energies 2012, 5(3):731-740.

36. Sang M, Wang M, Liu J, Zhang C, Li A: Effects of temperature, salinity, light intensity, and $\mathrm{pH}$ on the eicosapentaenoic acid production of Pinguiococcus pyrenoidosus. J Ocean Univ China (English Edition) 2012, 11(2):1-6.

37. Scott SD, Armenta RE, Berryman KT, Norman AW: Use of raw glycerol to produce oil rich in polyunsaturated fatty acids by a thraustochytrid. Enzyme Microb Technol 2011, 48(3):267-272.

38. Yongmanitchai W, Ward OP: Growth of and omega-3 fatty acid production by Phaeodactylum tricornutum under different culture conditions. App/ Environ Microbiol 1991, 57(2):419-425.

39. Bhosale RA, Rajabhoj M, Chaugule B: Dunaliella salina Teod. as a prominent source of eicosapentaenoic acid. Int J Algae 2010, 12(2):185-189. 
40. Hu C, Li M, Li J, Zhu Q, Liu Z: Variation of lipid and fatty acid compositions of the marine microalga Pavlova viridis (Prymnesiophyceae) under laboratory and outdoor culture conditions. World J Microbiol Biotechnol 2008, 24(7):1209-1214.

41. Carvalho AP, Malcata FX: Optimization of $\omega-3$ fatty acid production by microalgae: crossover effects of $\mathrm{CO}_{2}$ and light intensity under batch and continuous cultivation modes. Mar Biotechnol 2005, 7(4):381-388.

42. Guihéneuf F, Mimouni V, Ulmann L, Tremblin G: Combined effects of irradiance level and carbon source on fatty acid and lipid class composition in the microalga Pavlova lutheri commonly used in mariculture. J Exp Mar Biol Ecol 2009, 369(2):136-143.

43. Yago T, Arakawa H, Morinaga T, Yoshie-Stark Y, Yoshioka M: Effect of wavelength of intermittent light on the growth and fatty acid profile of the haptophyte Isochrysis galbana. Glob Chang: Mank-Mar Environ Interact 2011, 43-45.

44. Park J-H, Yoon J-J, Park H-D, Kim YJ, Lim DJ, Kim S-H: Feasibility of biohydrogen production from Gelidium amansii. Int I Hydrogen Energ 2011, 36(21):13997-14003.

45. Becker EW: Micro-algae as a source of protein. Biotechnol Adv 2007, 25(2):207-210

46. Harwood JL, Guschina IA: The versatility of algae and their lipid metabolism. Biochimie 2009, 91(6):679-684.

47. Sellner KG, Doucette GJ, Kirkpatrick GJ: Harmful algal blooms: causes, impacts and detection. I Ind Microbiol Biotechnol 2003, 30(7):383-406.

48. Anderson D, Glibert P, Burkholder J: Harmful algal blooms and eutrophication: nutrient sources, composition, and consequences. Estuar Coast 2002, 25(4):704-726.

49. Brown MR: Nutritional value and use of microalgae in aquaculture. Avances en Nutrición Acuícola VI Memorias del VI Simposium Internacional de Nutrición Acuícola 2002, 3:281-292.

50. Foster C: Aquaculture production to double by 2015. In The fish site. Edited by. 2008.

51. Australian bureau of agricultural and resource economics. Australian fisheries production falls. http://www.thefishsite.com/fishnews/10374/ australian-fisheries-production-falls.

52. Caers M, Coutteau P, Sorgeloos P, Gajardo G: Impact of algal diets and emulsions on the fatty acid composition and content of selected tissues of adult broodstock of the chilean scallop Argopecten pupuratus (Lamarck, 1819). Aquaculture 2003, 217(1-4):437-452.

53. Soudant P, Marty Y, Moal J, Samain J: Fatty acids and egg quality in great scallop. Aquac Int 1996, 4(3):191-200.

54. Utting SD, Millican PF: The role of diet in hatchery conditioning of Pecten maximus L.: a review. Aquaculture 1998, 165(3-4):167-178.

55. Torrissen OJ: Pigmentation of salmonids - a comparison of astaxanthin and canthaxanthin as pigment sources for rainbow trout. Aquaculture 1986, 53(3-4):271-278.

56. Brown M: Nutritional value of microalgae for aquaculture. In Avances en nutrición acuícola VI memorias del VI simposium internacional de nutrición. Edited by Cruz-Suárez LE, Ricque-Marie D, Tapia-Salazar M, Gaxiola-Cortés MG, Simoes NE. Cancún, Quintana Roo, México; 2002.

57. Borowitzka M: Microalgae for aquaculture: opportunities and constraints. J Appl Phycol 1997, 9(5):393-401.

58. Benemann J: Microalgae aquaculture feeds. J Appl Phycol 1992, 4(3):233-245.

59. Brunner E: Oily fish and omega 3 fat supplements. BMJ 2006, 332(7544):739-740

60. Sijtsma L, Swaaf ME: Biotechnological production and applications of the n-3 polyunsaturated fatty acid docosahexaenoic acid. Appl Microbiol Biotechnol 2004, 64(2):146-153.

61. Horrocks LA, Yeo YK: Health benefits of docosahexaenoic acid (DHA). Pharmacol Res 1999, 40(3):211-225.

62. Simopoulos AP, Bazán NG, Karger S: Omega-3 fatty acids, the brain and retina: Karger; 2009

63. Damude HG, Kinney AJ: Enhancing plant seed oils for human nutrition. Plant Physiol 2008, 147(3):962-968.

64. Dyerberg J, Leaf A, GA C: ISSFAL board statement: recommendations for the essential fatty acid requirement for infant formulas. J Am Coll Nutr $1995,14: 2$.

65. Hibbeln JR, Salem N Jr: Dietary polyunsaturated fatty acids and depression: when cholesterol does not satisfy. Am J Clin Nutr 1995, 62(1):1-9.
66. Simopoulos AP: Omega-3 fatty acids in health and disease and in growth and development. Am J Clin Nutr 1991, 54(3):438-463.

67. Calder PC: Sir david cuthbertson medal lecture. Immunomodulatory and anti-inflammatory effects of $n-3$ polyunsaturated fatty acids. Proc Nutr Soc 1996, 55(2):737-774.

68. Hodge L, Salome CM, Peat JK, Haby MM, Xuan W, Woolcock AJ: Consumption of oily fish and childhood asthma risk. Med J Aust 1996, 164(3):137-140

69. Stenson WF, Cort D, Rodgers J, Burakoff R, DeSchryver-Kecskemeti K, Gramlich TL, Beeken W: Dietary supplementation with fish oil in ulcerative colitis. Ann Intern Med 1992, 116(8):609-614.

70. Simopoulos AP: Omega-3 fatty acids in inflammation and autoimmune diseases. J Am Coll Nutr 2002, 21(6):495-505.

71. CODIF Recherche \& Nature: DERMOCHLORELLA D - DERMOCHLORELLA DP skin restructuring. In St Malo cedex. Edited by. France: CODIF Recherche \& Nature; 2006.

72. Exymol SAM: Protulines: Spirulina extract. In Exymo/ SAM. Edited by. Monaco:; 2012.

73. Tiez L, Zeiger E: Plant physiology. 5th edition. Sunderland: Sinauer Associates Inc, Publishers; 2010.

74. Cohen Z, Khozin-Goldberg I, Adlerstein D, Bigogno C: The role of triacylglycerol as a reservoir of polyunsaturated fatty acids for the rapid production of chloroplastic lipids in certain microalgae. Biochem Soc Trans 2000, 28(6):740-744.

75. Sukenik A: Ecophysiological considerations in the optimization of eicosapentaenoic acid production by Nannochloropsis sp. (Eustigmatophyceae). Bioresour Technol 1991, 35(3):263-269.

76. Burja AM, Radianingtyas $\mathrm{H}$, Windust $\mathrm{A}$, Barrow $\mathrm{CJ}$ : Isolation and characterization of polyunsaturated fatty acid producing Thraustochytrium species: screening of strains and optimization of omega-3 production. Appl Microbiol Biotechnol 2006, 72(6):1161-1169.

77. Zhu L, Zhang X, Ji L, Song X, Kuang C: Changes of lipid content and fatty acid composition of Schizochytrium limacinum in response to different temperatures and salinities. Process Biochem 2007, 42(2):210-214.

78. Griffiths MJ, Harrison STL: Lipid productivity as a key characteristic for choosing algal species for biodiesel production. J Appl Phycol 2009, 21(5):493-507.

79. Singh SC, Sinha RP, Hader D: Role of lipids and fatty acids in stress tolerance in cyanobacteria. Acta protozoologica 2002, 41(4):297-308.

80. de Castro AS, Garcia VMT: Growth and biochemical composition of the diatom Chaetoceros cf. wighamii Brightwell under different temperature, salinity and carbon dioxide levels. I. Protein, carbohydrates and lipids. Aquaculture 2005, 246(4):405-412.

81. Otero A, García D, Fábregas J: Factors controlling eicosapentaenoic acid production in semicontinuous cultures of marine microalgae. $J$ App Phycol 1997, 9(5):465-469.

82. Wen $Z Y$, Chen F: Optimization of nitrogen sources for heterotrophic production of eicosapentaenoic acid by the diatom Nitzschia laevis. Enzyme Microb Technol 2001, 29(6-7):341-347.

83. Sheehan J, Dunahay T, Benemann J, Roessler P: A look back at the US department of energy's aquatic species program: biodiesel from algae, close out report TP-580-24190. In CO: national renewable energy laboratory. Edited by Golden: US Department of Energy's Office of Fuels Development, USA; 1998

84. Pal D, Khozin-Goldberg I, Cohen Z, Boussiba S: The effect of light, salinity, and nitrogen availability on lipid production by Nannochloropsis sp. Appl Microbiol Biotechnol 2011, 1-13.

85. Takagi M: Effect of salt concentration on intracellular accumulation of lipids and triacylglyceride in marine microalgae Dunaliella cells. J Biosci Bioeng 2006, 101(3):223-226.

86. Timmins M, Zhou W, Lim L, Thomas-Hall SR, Doebbe A, Kruse O, Hankamer B, Marx UC, Smith SM, Schenk PM: The metabolome of Chlamydomonas reinhardtii following induction of anaerobic $\mathrm{H}_{2}$ production by sulphur deprivation. J Biol Chem 2009,

87. Hu H, Gao K: Response of growth and fatty acid compositions of Nannochloropsis sp. to environmental factors under elevated $\mathrm{CO}_{2}$ concentration. Biotechnol Lett 2006, 28(13):987-992.

88. Tatsuzawa H, Takizawa E: Changes in lipid and fatty acid composition of Pavlova lutheri. Phytochemistry 1995, 40(2):397-400.

89. Jiang $\mathrm{H}$, Gao K: Effects of lowering temperature during culture on the production of polyunsaturated fatty acids in the marine diatom 
Phaeodactylum tricornutum (bacillariophyceae) 1. J Phycol 2004, 40(4):651-654

90. Liang Y, Beardall J, Heraud P: Effect of UV radiation on growth, chlorophyll fluorescence and fatty acid composition of Phaeodactylum tricornutum and Chaetoceros muelleri (bacillariophyceae). Phycologia 2006, 45(6):605-615.

91. Schuhmann H, Lim DKY, Schenk PM: Perspectives on metabolic engineering for increased lipid contents in microalgae. Biofuels 2012, 3(1):71-86.

92. Wagner M, Hoppe K, Czabany T, Heilmann M, Daum G, Feussner I, Fulda M: Identification and characterization of an acyl-CoA: diacylglycerol acyltransferase 2 (DGAT2) gene from the microalga O. tauri Plant Physiol Biochem 2010, 48(6):407-416.

93. Xu J, Zheng Z, Zou J: A membrane-bound glycerol-3-phosphate acyltransferase from Thalassiosira pseudonana regulates acyl composition of glycerolipids. Botany 2009, 87(6):544-551.

94. Tonon T, Sayanova O, Michaelson LV, Qing R, Harvey D, Larson TR, Li Y, Napier JA, Graham IA: Fatty acid desaturases from the microalga Thalassiosira pseudonana. FEBS J 2005, 272(13):3401-3412.

95. Tonon T, Qing R, Harvey D, Li Y, Larson TR, Graham IA: Identification of a long-chain polyunsaturated fatty acid acyl-coenzyme A synthetase from the diatom Thalassiosira pseudonana. Plant Physiol 2005, 138(1):402-408.

96. Domergue F, Lerchl J, Zähringer U, Heinz E: Cloning and functional characterization of tricornutum front-end desaturases involved in eicosapentaenoic acid biosynthesis. Eur J Biochem 2002, 269(16):4105-4113.

97. Domergue F, Spiekermann P, Lerchl J, Beckmann C, Kilian O, Kroth PG, Boland W, Zähringer U, Heinz E: New insight into Phaeodactylum tricornutum fatty acid metabolism. Cloning and functional characterization of plastidial and microsomal $\Delta 12$-fatty acid desaturases. Plant Physiol 2003, 131(4):1648-1660.

98. Chi X, Zhang X, Guan X, Ding L, Li Y, Wang M, Lin H, Qin S: Fatty acid biosynthesis in eukaryotic photosynthetic microalgae: identification of a microsomal delta 12 desaturase in Chlamydomonas reinhardtii. J Microbiol 2008, 46(2):189-201.

99. Hu Q, Sommerfeld M, Jarvis E, Ghirardi M, Posewitz M, Seibert M, Darzins A: Microalgal triacylglycerols as feedstocks for biofuel production: perspectives and advances. Plant J 2008, 54(4):621-639.

100. Pereira SL, Leonard AE, Mukerji P: Recent advances in the study of fatty acid desaturases from animals and lower eukaryotes. Prostaglandin Leukot Essent Fat Acid 2003, 68(2):97-106.

101. Amiri Jami M, Griffiths M: Recombinant production of omega 3 fatty acids in Escherichia coli using a gene cluster isolated from Shewanella baltica MAC1. J Appl Microbiol 2010.

102. Li YT, Li MT, Fu CH, Zhou PP, Liu JM, Yu LJ: Improvement of arachidonic acid and eicosapentaenoic acid production by increasing the copy number of the genes encoding fatty acid desaturase and elongase into Pichia pastoris. Biotechnol Lett 2009, 31(7):1011-1017.

103. Bligh E, Dyer W: A rapid method of total lipid extraction and purification. Can J Biochem Physiol 1959, 37(8):911-917.

104. Engström K, Saldeen AS, Yang B, Mehta JL, Saldeen T: Effect of fish oils containing different amounts of EPA, DHA, and antioxidants on plasma and brain fatty acids and brain nitric oxide synthase activity in rats. Ups J Med Sci 2009, 114(4):206-213.

105. Hickman KCD: Vacuum distillation apparatus. In Google patents. Edited by. 1939.

106. Barrer RM, Ruiz JLLÓP: Glycerolysis of methyl esters of fatty acids using molecular sieves. J App/ Chem Biotechnol 1973, 23(3):189-194.

107. Schlenk H, Gellerman JL: Esterification of fatty acids with diazomethane on a small scale. Anal Chem 1960, 32(11):1412-1414.

108. Francis AW: Ternary systems of liquid carbon dioxide. J Phys Chem 1954, 58(12):1099-1114.

109. Bengen F: German patent application OZ 12438. March 1940, 18:135-139

110. Eckey EW: Directed interesterification in glycerides. Ind Eng Chem 1948 , 40(7):1183-1190

111. Reitan Kl, Rainuzzo JR, Øie G, Olsen Y: A review of the nutritional effects of algae in marine fish larvae. Aquaculture 1997, 155(1-4):207-221.

112. Andrich G, Nesti U, Venturi F, Zinnai A, Fiorentini R: Supercritical fluid extraction of bioactive lipids from the microalga Nannochloropsis sp. Eur J Lipid Sci Tech 2005, 107(6):381-386.
113. Herrero M, Cifuentes A, Ibañez E: Sub- and supercritical fluid extraction of functional ingredients from different natural sources: plants, food-byproducts, algae and microalgae: a review. Food Chem 2006, 98(1):136-148.

114. Subhadra B: Algal biorefinery based industry: an approach to address fuel and food insecurity for a carbon smart world. J Sci Food Agric 2011, 91(1):2-13.

115. Subhadra BG: Sustainability of algal biofuel production using integrated renewable energy park (IREP) and algal biorefinery approach. Energ Pol 2010, 38(10):5892-5901.

doi:10.1186/1475-2859-11-96

Cite this article as: Adarme-Vega et al:: Microalgal biofactories: a promising approach towards sustainable omega-3 fatty acid production. Microbial Cell Factories 2012 11:96.

\section{Submit your next manuscript to BioMed Central and take full advantage of:}

- Convenient online submission

- Thorough peer review

- No space constraints or color figure charges

- Immediate publication on acceptance

- Inclusion in PubMed, CAS, Scopus and Google Scholar

- Research which is freely available for redistribution 